\title{
P333: Understanding patient safety in Angola: a situational analysis at hospital Américo Boavida
}

\author{
JC Correia ${ }^{1 *}$, L Antunes ${ }^{2}$, JD Hightower ${ }^{3}$, SB Syed ${ }^{4}$ \\ From 2nd International Conference on Prevention and Infection Control (ICPIC 2013) \\ Geneva, Switzerland. 25-28 June 2013
}

\section{Introduction}

There is an increasing commitment in the African Region towards patient safety (PS) in hospitals, following acknowledgement that it is an important public health issue which needs to be addressed in order to improve population health.

\section{Objectives}

To define the state of PS at Américo Boavida Hospital (HAB) in Luanda and thus enhance understanding of PS in Angola.

\section{Methods}

Patient Safety Situational Analysis tool co-developed by WHO African Partnerships for Patient Safety was utilized. Data was gathered by a hospital team based on responsibilities in each of 12 PS areas, coordinated by an analysis lead. Data were analysed in each PS area, with a specific focus on infection prevention \& control (IPC).

\section{Results}

Approximately two-thirds of PS questions asked were answered affirmatively for HAB. For IPC approximately $60 \%$ of questions had a positive response .Specific findings include: 1. multidisciplinary IPC hospital team but no doctor or nurse assigned full time to activities; 2 . occupational medicine service conducts health worker IPC training; 3. adequate reliable supply of soap and alcohol based handrub; 4. hospital posters on hand hygiene and IPC; 5 . microbiology service with capacity for microscopy and aerobic culture; 6 . lack of triaging and isolation policy of patients at high risk of transmission of infections.
In other areas, PS knowledge \& learning, as well as PS \& systems development had $90 \%$ positive responses. In medication safety, health worker protection and PS research \& surveillance, affirmative responses averaged $80 \%$. Health care waste management, linkage with national policies, PS funding and partnerships for PS revealed affirmative answers to questions posed of $60 \%, 50 \%, 40 \%$ and $25 \%$ respectively.

\section{Conclusion}

Self-reported data quality is subject to bias. However, selfassessment can catalyze internally driven hospital improvement. This first analysis serves as a robust PS baseline to plan hospital action to address shortcomings. Repeat PS situational analysis can track progress. The approach can also be replicated across hospitals in Angola to guide national action. Further, the areas of strength at HAB (identified through the PS analysis) can serve as a resource for hospitals in Angola.

\section{Disclosure of interest}

None declared.

\section{Author details}

${ }^{1}$ Health, Permanent Mission of Angola, Geneva, Switzerland. ${ }^{2}$ Americo Boavida Hospital, Luanda, Angola. ${ }^{3}$ African Partnerships for Patient Safety World Health Organization, Harare, Zimbabwe. ${ }^{4}$ African Partnerships for Patient Safety, World Health Organization, Geneva, Switzerland.

\section{Published: 20 June 2013}

\section{doi:10.1186/2047-2994-2-S1-P333}

Cite this article as: Correia et al:: P333: Understanding patient safety in Angola: a situational analysis at hospital Américo Boavida. Antimicrobial Resistance and Infection Control 2013 2(Suppl 1):P333.

${ }^{1}$ Health, Permanent Mission of Angola, Geneva, Switzerland

Full list of author information is available at the end of the article

(c) 2013 Correia et al; licensee BioMed Central Ltd. This is an Open Access article distributed under the terms of the Creative Commons Attribution License (http://creativecommons.org/licenses/by/2.0), which permits unrestricted use, distribution, and reproduction in any medium, provided the original work is properly cited. 